\title{
Effect of Nanosilica on shrinkage strain of low- binder ultrahigh performance cementitious composites
}

\author{
[Diler Sabah Asaad, Mehmet Gesoglu, Erhan Güneyisi, Osman Hansu]
}

\begin{abstract}
This study demonstrated the effect of using nano silica (NS) on the shrinkage properties of low binder ultra-high performance cementitious composites (UHPCCs). For this, UHPCC mixtures were designed with water/binder ratio of 0.20 and total binder of $800 \mathrm{~kg} / \mathrm{m}^{3}$. Commercially available NS was used in partial substitution of cement at $0,0.5,1,2$ and $3 \%$ by weight. The samples produced were tested for compressive strength, autogenous and drying shrinkage as well as weight loss. The results showed that replacing of NS with cement decreased both dry and autogenous shrinkage of UHPCCs. Furthermore, among different NS contents ranging from 0.5 to $3 \%$, UHPCCs containing $2 \%$ NS exhibited better results of compressive strength at 180 days.
\end{abstract}

Keywords - Nanosilica; ultrahigh performance composite; shrinkage; compressive strength

\section{Introduction}

During the last 20 years, Ultra-High Performance Concrete cementitous composites (UHPCC) has become an introduction of the most favorable ingenious high technology types of concrete [1-3]. In order to obtain the desired properties of UHPCC, enhancing the interfacial transition zone (ITZ) to a level comparable to that of bulk paste aggregate. This might be achieved by using silica materials such as nano silica (NS) [4]. Nano-scale $\mathrm{SiO}_{2}$ seems to be the most popular nano-particle in the researches because of its big benefits in the concrete. Nano $\mathrm{SiO}_{2}$ cannot only fill the voids between cement and silica fume particles; its high specific surface area to the volume ratio yields a high rate of pozzolanic reaction that leads to the potential for tremendous chemical activity. Recent studies revealed that addition of nano-silica provided many significant improvement in mechanical [5], durability [6], physical [7] and micro structure of concretes [8]. Nevertheless, there are divergent opinion and poor vision about the optimum percentage of the nano-sized particles when replaced with cement to produce concrete. There are little studies on shrinkage properties of UHPCC containing nano materials in which the effect of such material is varying and contradictory. On the other hand, concerning to the effect of NS on UHPCC, there is no doubt of increasing mechanical properties among researchers especially compressive strength $[9,10]$.

\section{Experimental study}

\section{A. Materials and mixture proportioning}

The cementitious materials used in concrete production were ordinary portland cement (CEM I 42.5 R) conforming to the TS EN 197 [11] and nano silica (NS). Chemical composition, physical and mechanical properties of them are given in Table 1. Quartz aggregate with a specific gravity of 2.65 was utilized in three fractions, namely $0-0.4,0.6-1.2$, and 1.2-2.5 mm. A new-generation superplasticizer (SP) of polycarboxilate type was used to fulfill the workability specifications in ASTM C 494 [12].

A comprehensive experimental program has been carried out and demonstrated in Table 2 with a NS content of $0,0.5$, 1,2 and $3 \%$. Superplasticizer was used in varying amounts to adjust the workability for the mixtures. The mixtures in Table 2 were designated according to NS replacement level, for example, NS1 indicates the mixture containing $1 \%$ of nano silica.

\section{B. Concrete mixture proportioning, casting, and sample preparation}

The mixtures were prepared by means of a special designed, vertical axis, high speed mixer which has mixing speed of as high as $470 \mathrm{rpm}$. Dry powders and aggregates were mixed with the speed of $100 \mathrm{rpm}$ for about three min. After a half of water addition, mixture was remixed for about five minutes with the speed of $100 \mathrm{rpm}$. Finally, SP and remaining water were added to premixed material and mixing was resumed at $470 \mathrm{rpm}$ for about five minutes. Fresh concretes were then poured into the molds and compacted by using a vibrating table. The specimens were then covered with polyethylene sheets and kept in the moulds for $16 \mathrm{~h}$ at room temperature of $22 \pm 2{ }^{\circ} \mathrm{C}$. Thereafter, they were cured in standard conditions of water curing until the testing age. In addition to $50-\mathrm{mm}$ cubes to determine compressive strength, a typical mixture consists of 70x70x280 mm dimensions for measuring each of weight loss, dry and autogenous shrinkage. 
Table 1 PROPERTIES OF CEMENT AND NANO SILICA

\begin{tabular}{|c|c|c|}
\hline Constituent (\%) & Cement & Nano silica \\
\hline $\mathrm{CaO}$ & 62.12 & - \\
\hline $\mathrm{SiO}_{2}$ & 19.69 & 99.8 \\
\hline $\mathrm{Al}_{2} \mathrm{O}_{3}$ & 5.16 & - \\
\hline $\mathrm{Fe}_{2} \mathrm{O}_{3}$ & 2.88 & - \\
\hline $\mathrm{MgO}$ & 1.17 & - \\
\hline $\mathrm{SO}_{3}$ & 2.63 & - \\
\hline $\mathrm{K}_{2} \mathrm{O}$ & 0.88 & - \\
\hline $\mathrm{Na}_{2} \mathrm{O}$ & 0.17 & - \\
\hline $\mathrm{Cl}$ & 0.0093 & - \\
\hline Loss on ignition & 2.99 & - \\
\hline Insoluble residue & 0.16 & - \\
\hline Free CaO & 1.91 & - \\
\hline Specific surface $\left(\mathrm{m}^{2} / \mathrm{kg}\right)$ & $394{ }^{\mathrm{a}}$ & $150000^{\mathrm{b}^{*}}$ \\
\hline Specific gravity & 3.15 & 2.2 \\
\hline
\end{tabular}

${ }^{a}$ Blaine specific surface area.

${ }^{\mathrm{b}}$ BET specific surface area.

TABLE 2 MIXTURE PROPORTIONS OF UHPCC CONTAINING NS

\begin{tabular}{|c|c|c|c|c|c|}
\hline Codes & $\begin{array}{c}\text { Cement } \\
(\mathbf{k g} / \mathbf{m 3})\end{array}$ & $\begin{array}{c}\text { Nano } \\
\text { Silica } \\
\left(\mathbf{k g} / \mathbf{m}^{3}\right)\end{array}$ & $\begin{array}{c}\text { Water } \\
(\mathbf{k g} / \mathbf{m 3})\end{array}$ & $\begin{array}{c}\text { SP }^{*} \\
(\mathbf{k g} / \mathbf{m 3})\end{array}$ & $\begin{array}{c}\text { Quartz } \\
\text { aggregate } \\
(\mathbf{k g} / \mathbf{m 3})\end{array}$ \\
\hline NS0 & 800 & 0 & 160 & 21.6 & 1471.3 \\
\hline NS0.5 & 796 & 4 & 160 & 25.2 & 1461.1 \\
\hline NS1 & 792 & 8 & 160 & 28.8 & 1450.8 \\
\hline NS2 & 784 & 16 & 160 & 36.0 & 1430.2 \\
\hline NS3 & 776 & 24 & 160 & 43.2 & 1409.7 \\
\hline
\end{tabular}

\section{Testing Methods}

Compression test was conducted on $50 \mathrm{~mm}$ cubes at 180 days with respect to ASTM C39 [13]. Free shrinkage specimens were exposed to drying in a room at $23 \pm 2{ }^{\circ} \mathrm{C}$ and $50 \pm 5 \%$ relative humidity for about 60 days, according to ASTM C157-75 [14]. A dial gage extensometer with a 200 $\mathrm{mm}$ gage length was used to measure the length change. Measurements were carried out every $24 \mathrm{hrs}$ for the first three weeks continuously and then three times a week. Variations in the free shrinkage strain and the weight loss were monitored at the same time on the same specimens. Free shrinkage measurements and weight loss of UHPCC were conducted on three prisms samples from each mixture. Like the dry shrinkage, the same size of prisms $(70 \times 70 \times 280$ $\mathrm{mm}$ ) and dial gage extensometer were used for measuring autogenous shrinkage test. Unless, a teflon sheet was placed inside the mold to prevent the restraint of concrete from the frictional force between the molds and UHPCCs. The top surface of the specimen was sealed with polyester film after the mold was filled completely to prevent moisture evaporation. After 24 hours, specimens were demolded immediately and sealed with aluminum adhesive tape to be performed in the equivalent constant temperature and indicated humidity room.

\section{Test results and discussions}

\section{A. Compressive strength}

Effects of using nano silica (NS) on the compressive strength development of the UHPCC are shown in Figures 1. Interestingly compressive strength of the concretes continuously increased up to $2 \%$ NS content beyond which strength began to decrease at 180 days. The control UHPCCs had 180-day compressive strengths of 136.5 as seen in Fig. 1. In addition, $2 \%$ NS replacement caused 10.5 $\%$ higher strengths than the companion reference mixtures. Furthermore, slightly lower compressive strength of UHPC containing 3\% NS may be attributed to improper dispersion of nano particles in the mixture. Nanoparticles have a pronounced tendency towards agglomeration because they have high inter-particle van der Waal's forces due to their much smaller sizes [15-17]. The disagglomeration of nanoparticles is crucial to achieve the ideal composite materials and the amount of $\mathrm{SiO}_{2}$ nano particles in the mixture can also have been exceeded the quantity for consuming the calcium hydroxide compounds to form C-S$\mathrm{H}$ gel. Therefore, it did not contribute to enhance the strength of UHPCC more [18]. Moreover, Table 2 presents the superplasticizer demand of the mixtures to provide the target workability. It was also evident in Fig. 2 that the mixtures with NS required greater amount of superplasticizer, especially at higher replacement levels of NS. The quite limited strength enhancement with the use of NS was also attributed to the increase in the superplasticizer for the sake of constant workability (Fig. 2).

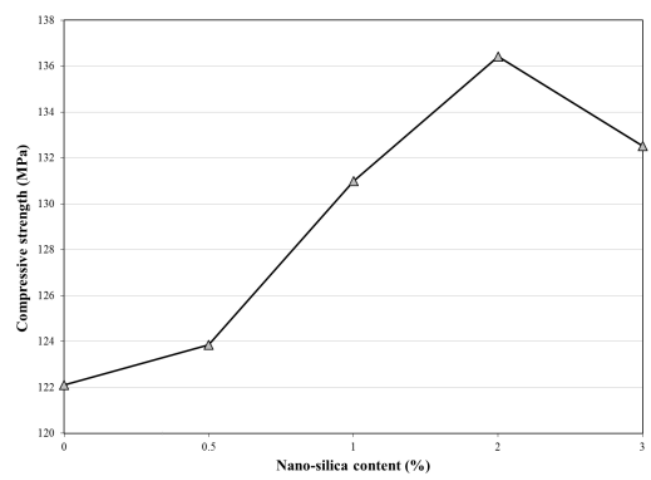

Fig. 1. Compressive strength versus Nano silica and water cured $\rightarrow-\mathrm{SP} \%$ - - flow $(\mathrm{mm})$

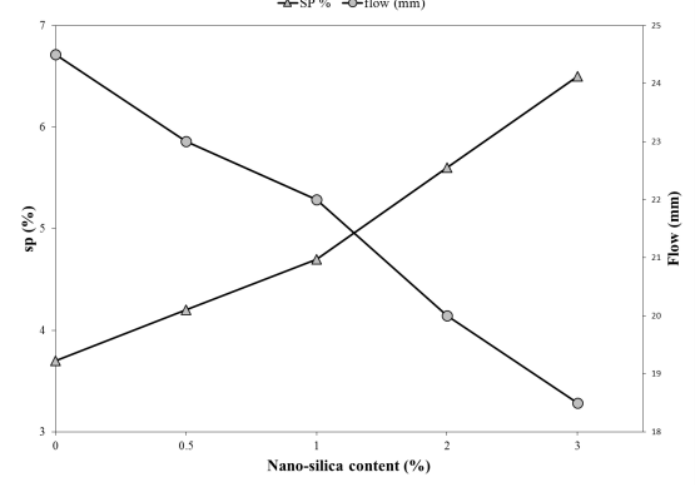

Fig. 2. Nano silica effective on flow and superplasticizer

\section{B. Free shrinkage, weight loss and flow}

The obtained dry shrinkage and weight loss results are demonstrated in Figs. 3 and 4, respectively. Though the dry 
shrinkage strains were comparable for the early ages of drying period, a clear distinction was observed at the later periods for UHPCC with different amount of NS content (Fig.3). The mixture that with no contribution of NS (NS0), had the highest shrinkage strain of about 519 microstrain at the end of the 60 days. In all UHPCCs mixes, the dry shrinkage reduces with an increase in the amount of NS. The use of NS with the amounts of $0.5 \%, 1 \%, 2 \%$ and $3.0 \%$ causes a reduction in dry shrinkage about $3 \%, 6 \%, 9 \%$ and $12 \%$, respectively. These dry shrinkage reduction effects of NS in UHPCC have also observed for normal concretes as reported [19-21] and were related with the main compound of NS which is assumed causing to reduce the surface force tension of pore water and consequently reducing the dry shrinkage [10/22].

As presented in Fig. 4, the weight loss values for UHPCCs containing more silica nano particles were slightly higher than that of lower nano silica content. The maximum difference of weight loss values between the mixture with zero and $3 \%$ of nano silica content (NSO and NS3) was equal to only $4.5 \mathrm{~g}$. The reason of faintly more loss of weight with the contribution of NS may be related to high superplasticizer used to achieve target workability for the mixes with high NS used, as noticed in Fig 2. On the other hand, this contradiction between dry shrinkage and weight loss was also explained by the other researchers like Wiegrink et al. [23], that the some other factors will interfere to this intimate relation.

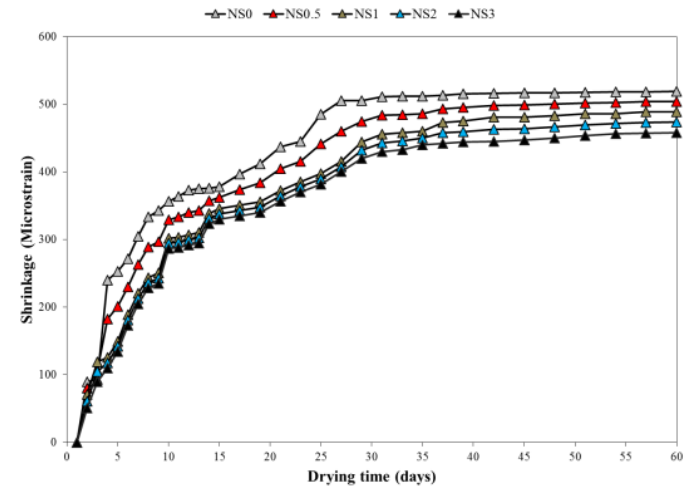

Fig. 3. Dry shrinkage measurements for UHPCC with different NS content.

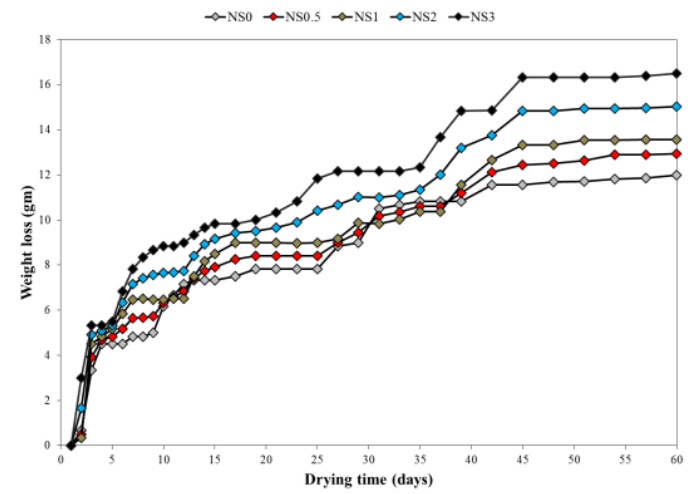

Fig. 4. Weight loss measurements for UHPCC with different NS content.

\section{Autogenous shrinkage}

The reduction of the macroscopic volume of cementitious composite by the hydration process, namely autogenous shrinkage, is strongly affected by admixtures and W/B [24, 25]. The measurement of autogenous shrinkage start with the starting of the initial setting time because this type of shrinkage usually used for the prediction of cracking so that the reduction of volume in the fresh state (before initial set) is excluded [26].

Typical autogenous shrinkage versus time curves for the UHPCCs with different amount of silica nano particles are displayed in Fig. 5. The lowest autogenous shrinkage (252 microstrain) was measured in the UHPCC with $3 \%$ of nano silica, followed by the concretes with lower NS content and it's finaly reached to 320 microstrain for zero nano silica content. Furthermore, using autogenous type will cause an extra improvement of shrinkage than the dry one, it is reached to $45 \%$ with a $3 \%$ incorporation of NS with UHPCC, as shown in Figs. 4 and 5.

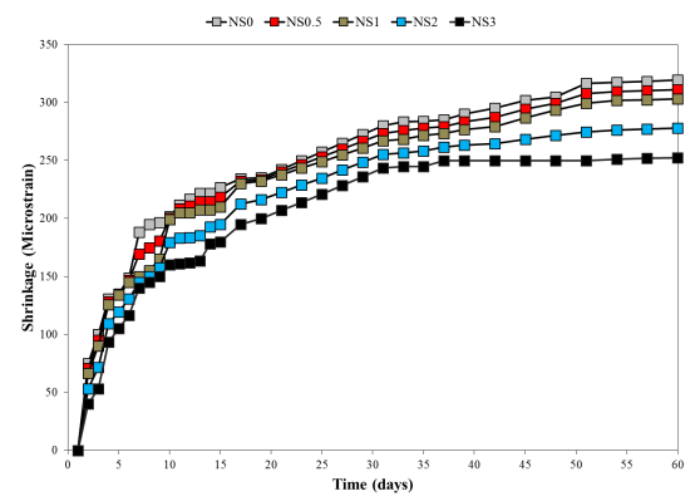

Fig. 5. Autogenous shrinkage measurements for UHPCC with different NS content.

\section{Conclusions}

The following conclusions can be excluded from this study:

1-NS increases the packing density, particularly interface between the pastes and aggregate. $3 \%$, the results were still higher than those of the control concrete (0\% NS).

2-UHPCC with low binder content $\left(800 \mathrm{~kg} / \mathrm{m}^{3}\right)$ and with no contribution of micro silica and steel fiber gave a compressive strength about $136.5 \mathrm{MPa}$, with only $2 \%$ of NS used in the mixture. Additionally, the quite limited strength enhancement with the use of NS was attributed to the increase in the superplasticizer for the sake of constant workability.

3-In all UHPCCs mixes, the dry shrinkage reduces with an increase in the amount of NS. The mixture that with no contribution of NS had the highest shrinkage strain is about 519 microstrain at the end of the 60 days drying period.

4-The weight loss values for UHPCCs containing more silica nanoparticles were slightly higher than that of lower nanosilica content. The maximum difference of weight loss values between the mixture with zero and $3 \%$ of nano silica content (NS0 and NS3) was equal to only $4.5 \mathrm{~g}$.

5-The reason of faintly more loss of weight with the contribution of NS, may related to high super plasticizer 
used to give enough workable for the mixes with high NS used and the some other factors will interfere to this intimate relation (shrinkage and weight loss).

6-The lowest autogenous shrinkage (252 microstrain) was measured in the UHPCC with $3 \%$ of nano Silica type, followed by the concretes with lower NS content and it's reached to 320 microstrain for zero silica content. Furthermore, using autogenous type will cause an extra improvement of shrinkage than the dry one, it is reached to $45 \%$ with a $3 \%$ incorporation of NS with UHPCC.

\section{References}

[1] P. Acker, M. Behloul, "DUCTAL_Technology: A large spectrum of properties, a wide range of applications," First International Symposium on Ultra High Performance Concrete. Kasesel, Germany 2004.

[2] M. Rebentrost, and G.W, "Experience and applications of Ultra-high Performance concrete in asia in Second International Symposium on Ultra High Performance Concrete," Kassel, Germany 2008.

[3] M.S. Fehling, and S. Stürwald, editor, The Third International Symposium on Ultra High Performance Concrete and Nanotechnology for High Performance Construction Materials. Kassel, Germany: Kassel University Press March 2012.

[4] J. Smith, G. Cusatis, D. Pelessone, E. Landis, J. O’Daniel, and J. Baylot, "Discrete modeling of ultra-high-performance concrete with application to projectile penetration," International Journal of Impact Engineering 65 (2014) $13 \mathrm{e} 32$

[5] F.T. Behrooz, B. M. Maher, and M.M. Shokrieh, "Mechanical properties modification of a thin film phenolic resin filled with nano silica particles," Computational Materials Science 96 (2015) 411-415.

[6] H. Du, S. Du, and X. Liu, "Durability performances of concrete with nano-silica," Construction and Building Materials 73 (2014) 705-712.

[7] M. Aly, M. S. J. Hashmi, A. G. Olabi. M. Messeiry, E. F. Abadir, and A. I. Hussain, "Effect of colloidal nano-silica on the mechanical and physical behaviour of waste-glass cement mortar," Materials and Design 33 (2012) 127-135.

[8] M. Oltulu, and R. Sahin, "Pore structure analysis of hardened cement mortars containing silica fume and different nano-powders," Construction and Building Materials 53 (2014) 658-664.

[9] Zh. Rong, W. Sun, H. Xiao, and G. Jiang, "Effects of nano-SiO2 particles on the mechanical and microstructural properties of ultrahigh performance cementitious composites," Cement \& Concrete Composites 56 (2015) 25-31.

[10] R. Yu, P. Spiesz, and H. J. H. Brouwers, "Effect of nano-silica on the hydration and microstructure development of Ultra-High Performance Concrete (UHPC) with a low binder amount," Construction and Building Materials 65 (2014) 140-150.

[11] TS EN 197-1, Cement- Part 1: Composition, specifications and conformity criteria for common cements, Turkish Standards; 2002.

[12] ASTM C494 / C494M-13, Standard Specification for Chemical Admixtures for Concrete, ASTM International, West Conshohocken, PA, 2013, www.astm.org.

[13] ASTM C39, Standard test method for compressive strength of cylindrical concrete specimens, Annual book of ASTM standard; 2012.

[14] B. Jo, C.H. Kim, G.h. Tae, and J.B. Park, "Characteristics of cement mortar with nano-SiO2 particles," Constr Build Mater 2007; 21:13515.

[15] G.Quercia, G.Hüsken, and H.J.H. Brouwers, "Water demand of amorphous nano silica and its impact on the workability of cement paste," Cement and Concrete Research 42 (2012) 344-357.

[16] G. Quercia, P. Spiesz, G. Husken, and J. Brouwers, "Effects of amorphous nano-silica additions on mechanical and durability performance of SCC mixtures," Proc. International congress on durability of concrete; 2012.
[17] L. Senff, D. Hotza, W.L. Repette, V.M. Ferreira, J.A. Labrincha, "Influence of added nanosilica and/or silica fume on fresh and hardened properties of moratrs and cement pastes," Adv Appl Ceram 2009;108(7):418-28.

[18] E. Ghafari, H. Costa, E. Júlio, A. Portugal, and L. Durães, "The effect of nanosilica addition on flowability, strength and transport properties of ultra high performance concrete," Mater Des 2014; 59:1-9.

[19] K.J. Folliard, and N.S. Berke, "Properties of high-performance concrete containing shrinkage-reducing admixture," Cem Concr Res 1997;27(9):1357-64.

[20] C. K. Nmai, R. Tomita, F. Hondo, and J. Buffenbarger, "Shrinkagereducing admixtures," Concr Int 1998;20(4):31-7.

[21] M. Shoya, S. Sugita, and T. Sugawara, "Improvement of drying shrinkage and shrinkage cracking of concrete by special surfactants. In: Vazquez E, editor. Admixtures for concrete," London: Chapman and Hall; 1990. p. 484-95.

[22] M. Shoya, and M. Sugita, "Application of special admixture to reduce shrinkage cracking of air dried concrete," Hachinohe Institute of Technology, Hachinohe, Japan; 1985. p. 1-11.

[23] K. Wiegrink, S.M. Marikunte, and S.P. Shah, "Shrinkage cracking of high strength concrete," ACI Mater J 1996;93(5):409-15.

[24] E. Tazawa, R. Sato, E. Sakai, and S. Miyazawa, Work of JCI committee on autogenous shrinkage. Shrinkage of Concrete. Shrinkage 2000. In: Baroghel-Bouny V, Aitcin P-C, editors, Proceedings of the international RILEM workshop, Paris, France; October 2000. p. 21-33.

[25] D. Y. Yoo, K. H. Min, J. H. Lee, and Y.S. Yoon, "Autogenous shrinkage of concrete with design strength from $60-120 \mathrm{~N} / \mathrm{mm} 2$," Mag Concr Res 2011;63(10):751-61.

[26] Japan Concrete Institute, Committee report. Autogenous shrinkage of concrete, In: Tazawa E, editor, E\&FN Spon; 1999. p. 3-62. 